\title{
Phase 2 study of lenvatinib monotherapy as second-line treatment in unresectable biliary tract cancer: primary analysis results
}

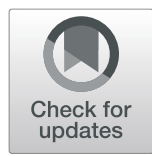

\author{
Makoto Ueno ${ }^{1 \dagger}$, Masafumi Ikeda ${ }^{2 * \dagger}$ D, Takashi Sasaki ${ }^{3}$, Fumio Nagashima ${ }^{4}$, Nobumasa Mizuno ${ }^{5}$, Satoshi Shimizu ${ }^{6}$, \\ Hiroki Ikezawa ${ }^{7}$, Nozomi Hayata ${ }^{7}$, Ryo Nakajima $^{8}$ and Chigusa Morizane ${ }^{9}$
}

\begin{abstract}
Background: Biliary tract cancer (BTC) has a poor prognosis and lacks a standardized second-line therapy. Vascular endothelial growth factor (VEGF), fibroblast growth factor receptor (FGFR) 4, and platelet-derived growth factor receptor (PDGFR) are highly expressed in BTC. Therefore, lenvatinib (a known inhibitor of VEGF receptors 1-3, FGFRs $1-4$, and PDGFR-a) was evaluated for second-line treatment of BTC.

Methods: In this single-arm, multicenter, open-label, phase 2 study, patients with BTC received lenvatinib $24 \mathrm{mg}$ orally once daily in 28-day cycles. The primary endpoint was objective response rate (ORR). Secondary endpoints included overall survival (OS), progression-free survival (PFS), PFS rate at 12 weeks, disease control rate, clinical benefit rate, safety and pharmacokinetic profiles.
\end{abstract}

Results: Twenty-six Japanese patients were enrolled and treated; 3 had a confirmed partial response per investigator assessment and per independent imaging review (IIR); ORR was 11.5\% (90\% confidence interval [CI]: 3.2-27.2). Median PFS was 3.19 months (95\% Cl: 2.79-7.23) per investigator assessment and 1.64 months (95\% Cl: 1.41-3.19) per IIR. Median OS was 7.35 months (95\% Cl: 4.50-11.27). Grade $\geq 3$ treatment-emergent adverse events (TEAEs) occurred in 21 patients (80.8\%) and included hypertension $(n=10$ [38.5\%]), proteinuria $(n=3[11.5 \%])$, palmar-plantar erythrodysesthesia ( $n=3[11.5 \%])$, decreased appetite $(n=3[11.5 \%])$, and anemia $(n=3[11.5 \%])$. Two deaths occurred due to TEAEs between treatment initiation and 30 days after last dose, but neither were considered treatment related.

Conclusions: Lenvatinib demonstrated antitumor activity in BTC, with a tolerable safety profile, and should be further evaluated as potential second-line therapy for this difficult to treat population.

Trial registration: ClinicalTrials.gov NCT02579616. Date of registration: October 19, 2015.

Keywords: Lenvatinib, Biliary tract cancer, Cholangiocarcinoma, Gallbladder cancer, Ampulla of Vater

\footnotetext{
* Correspondence: masikeda@east.ncc.go.jp

${ }^{\dagger}$ Makoto Ueno and Masafumi Ikeda contributed equally to this work.

${ }^{2}$ Department of Hepatobiliary and Pancreatic Oncology, National Cancer Center Hospital East, 6-5-1 Kashiwanoha, Kashiwa 277-8577, Japan

Full list of author information is available at the end of the article
}

(c) The Author(s). 2020 Open Access This article is licensed under a Creative Commons Attribution 4.0 International License, which permits use, sharing, adaptation, distribution and reproduction in any medium or format, as long as you give appropriate credit to the original author(s) and the source, provide a link to the Creative Commons licence, and indicate if changes were made. The images or other third party material in this article are included in the article's Creative Commons licence, unless indicated otherwise in a credit line to the material. If material is not included in the article's Creative Commons licence and your intended use is not permitted by statutory regulation or exceeds the permitted use, you will need to obtain permission directly from the copyright holder. To view a copy of this licence, visit http://creativecommons.org/licenses/by/4.0/ The Creative Commons Public Domain Dedication waiver (http://creativecommons.org/publicdomain/zero/1.0/) applies to the data made available in this article, unless otherwise stated in a credit line to the data. 


\section{Background}

Biliary tract cancer (BTC) is the second-mostcommon hepatobiliary cancer worldwide [1,2] and includes gallbladder cancer, intrahepatic cholangiocarcinoma, and extrahepatic cholangiocarcinoma [3]. Ampulla of Vater cancer is sometimes characterized as a biliary tract cancer $[1,3]$, although the National Comprehensive Cancer Network does not include it under hepatobiliary cancers [4]. BTC incidence increased 25\% worldwide between 2007 and 2017 (approximately 174,000 deaths) according to a Global Burden of Disease study [5]. A recent US study reported increasing incidence rates of gallbladder cancer in younger patients (<45 years of age; $1.8 \%$ increase per year) and African Americans [3]. Patients with BTC have a poor prognosis and a shortened life expectancy (typically $\leq 1$ year following diagnosis) $[1,6]$.

Currently, radical surgery is the only potentially curative therapy, but this is not an option for many patients who present with advanced disease [7]. The standard first-line therapy for BTC is gemcitabine and cisplatin (GC) [4]. Gemcitabine plus S-1 (GS) [8] and GC plus S-1 have demonstrated potential as first-line therapies [9]. Unfortunately, for patients who progress on or after first-line therapies there are no approved subsequent treatment options [4]. Thus, there is an unmet need for an effective second-line therapy for patients with BTC.

Vascular endothelial growth factor (VEGF), fibroblast growth factor receptor (FGFR) 4, and plateletderived growth factor receptor (PDGFR) are highly expressed in patients with BTC and correlate with a poor prognosis [10-13]. Lenvatinib is an oral multikinase inhibitor that targets VEGF receptors 1-3, FGFRs 1-4, PDGFR $\alpha$, RET, and KIT [14-17]. Lenvatinib monotherapy is approved for the treatment of radioiodine-refractory differentiated thyroid cancer (DTC) and first-line treatment of hepatocellular carcinoma in Japan, the United States, Europe, China, and several other countries [18].

The overexpression of VEGF, FGFR, and PDGFR in BTC suggests that lenvatinib could play a role in the treatment of BTC. This phase 2 study evaluated the safety and efficacy of lenvatinib as second-line therapy for patients with BTC [19].

\section{Methods}

\section{Study design}

This study (Study 215; NCT02579616) was a singlearm, multicenter, open-label, phase 2 study in Japanese patients with unresectable BTC. Patients received lenvatinib $24 \mathrm{mg}$ orally once daily in 28-daycycles. Treatment continued until development of an unacceptable toxicity, disease progression, withdrawal of consent, or documentation of significant violations of the prespecified inclusion/exclusion criteria.

The primary endpoint was objective response rate (ORR). Secondary endpoints included overall survival (OS), progression-free survival (PFS), PFS rate at 12 weeks, disease control rate (DCR), clinical benefit rate (CBR; the proportion of patients with complete response + partial response + durable stable disease [ $\geq 23$ weeks]), and safety and pharmacokinetic profiles. Tumor assessments were performed every 6 weeks until week 24 , and then every 8 weeks thereafter, utilizing Response Evaluation Criteria In Solid Tumors (RECIST), version 1.1, by investigator assessment for the primary analysis. Independent imaging review (IIR) was utilized to support the post hoc analysis. Complete or partial responses required confirmation $\geq 28$ days after the initial response.

The safety profile was assessed by monitoring and recording all adverse events (AEs), including all Common Terminology Criteria for Adverse Events, version 4.03, grades and serious AEs; periodic laboratory evaluations for hematology, blood chemistry, and urine values; periodic measurement of vital signs; electrocardiograms; and physical examinations. Toxicity was managed by supportive medications, treatment interruption, dose reduction (to $20 \mathrm{mg}, 14 \mathrm{mg}$, or $10 \mathrm{mg}$; re-escalation was not allowed), and/or treatment discontinuation in accordance with protocol-prespecified dose-modification guidelines. Briefly, hypertension was managed by initiating antihypertensives if blood pressure was $\geq 140 \mathrm{mmHg}$ (systolic) or $\geq 90 \mathrm{mmHg}$ (diastolic), and then by dose interruption and reduction if blood pressure was $\geq 160 \mathrm{mmHg}$ (systolic) or $\geq 90$ $\mathrm{mmHg}$ (diastolic), despite optimal management with antihypertensive medications. Lenvatinib was discontinued upon occurrence of any grade $\geq 4$ treatmentrelated AEs.

Plasma samples were collected from all patients on cycle 1, day 1 (C1D1; postdose), C1D8 (predose), C1D15 (pre/postdose), and C2D1 (predose) to assess the pharmacokinetic profile. Validated liquid chromatography with tandem mass spectrometry was utilized to determine lenvatinib plasma concentrations. Plasma concentrations were compared to the levels observed in patients from Study 303 (a phase 3 study of patients with DTC treated with lenvatinib $24 \mathrm{mg}$ once daily) [20].

The primary analysis was performed as planned at the data cut-off (November 22, 2016) when all patients had finished their week 32 tumor assessment or had discontinued treatment. All patients provided written informed consent. The study protocol, informed consent form and any related documents were 
submitted to an Institutional Review Board for approval. This study was conducted in accordance with the World Medical Association Declaration of Helsinki, Good Clinical Practices, and local ethical/ legal requirements.

\section{Eligibility}

Patients enrolled must have experienced disease progression or treatment failure following 1 prior gemcitabine-based chemotherapy regimen (in combination with cisplatin or other platinum agent/fluoropyrimidine agent). Pathologically or cytologically confirmed unresectable adenocarcinoma of BTC, measurable disease per RECIST version 1.1, and an Eastern Cooperative Oncology Group performance status (ECOG PS) score of 0 or 1 were required. Additionally, eligible patients were required to be $\geq 20$ years old with adequately controlled blood pressure $(\leq 150 / 90 \mathrm{mmHg})$, adequate blood coagulation, and major organ function.

Key exclusion criteria comprised: any anticancer treatment within 21 days prior to the first dose of study drug, bleeding/thrombotic disorders, meningeal carcinomatosis, unstable brain/subdural metastases, or New York Heart Association Class $\geq 2$ heart failure.

\section{Statistical analysis}

The sample size was determined based on the width of confidence interval (CI) using the 1-sample binomial distribution. Approximately, 25 patients were to be enrolled and if the true ORR was 15\%, 3 (90\% CI: 3.4-28.2) to 4 (90\% CI: 5.7-33.0) responses were expected. Efficacy and safety, and pharmacokinetic assessments were performed on all patients who received at least 1 dose of study drug. The ORR, DCR, CBR, and corresponding exact 2-sided 90\% CIs, were calculated using the Clopper-Pearson method. These endpoints were evaluated by investigator assessment and IIR. The Kaplan-Meier method was utilized to summarize OS, PFS, and PFS rate at 12 weeks. The Greenwood formula and log-log transformation were used to calculate the $95 \%$ CIs.

\section{Results}

\section{Patients}

This study enrolled 26 Japanese patients, and all patients received at least 1 dose of lenvatinib. Primary tumor locations included gallbladder $(n=10)$, extrahepatic bile duct $(n=8)$, intrahepatic bile duct $(n=6)$, and the ampulla of Vater $(n=2)$. Most patients were male (57.7\%), had an ECOG PS score of 0 (73.1\%), and had metastases of the lymph nodes (61.5\%) or liver (57.7\%) (Table 1). Additionally, the following baseline characteristics have previously demonstrated correlations with OS and/or PFS, and are shown in Table 1 according to the cutoff values used in previous research: white blood cell count, hemoglobin, alkaline phosphatase, albumin, and lesion size [7, 21].

\section{Efficacy}

The ORR following lenvatinib treatment was 11.5\% (90\% CI: 3.2-27.2) per investigator assessment; 3 patients (11.5\%) experienced a partial response, and 19 patients (73.1\%) achieved stable disease (Table 2). The median PFS was 3.19 months (95\% CI: 2.79-7.23) (Fig. 1), and the PFS rate at 12 weeks was $72.2 \%$ (95\% CI 50.4-85.7) per investigator assessment. The median OS was 7.35 months (95\% CI: 4.50-11.27; Fig. 2), and most patients experienced a reduction in tumor size (Fig. 3).

Additionally, the ORR per IIR was also $11.5 \%(90 \%$ CI: 3.2-27.2); 3 patients (11.5\%) experienced a partial response, and 9 patients (34.6\%) achieved stable disease (Table 2). The median PFS was 1.64 (95\% CI: 1.41-3.19) months, and the PFS rate at 12 weeks was 44.0\% (95\% CI: 24.5-61.9), both per IIR (Fig. 1). The DCR and CBR results per investigator assessment and IIR are shown in Table 2.

\section{Safety}

Treatment-emergent adverse events (TEAEs) are shown in Table 3; treatment-related AEs (Table 4) occurred in all 26 patients. The most common TEAEs (occurring in $\geq 50 \%$ of patients) were hypertension (84.6\%), dysphonia (61.5\%), proteinuria (61.5\%), palmar-plantar erythrodysesthesia syndrome (57.7\%), decreased appetite (53.8\%), thrombocytopenia (53.8\%), and fatigue (50\%) (Table 3). TEAEs of grade $\geq 3$ severity were reported in 21 patients. Two deaths occurred due to TEAEs (cholangitis, $n=1$; completed suicide, $n=1$ ) between the initiation of treatment and 30 days from the last dose, but neither were considered related to treatment by the investigators.

TEAEs led to treatment discontinuation in 2 patients (7.7\%; erythema multiforme, $n=1$; and lung abscess, $n=1$ ). However, most TEAEs were manageable: $76.9 \%$ $(20 / 26)$ of patients required lenvatinib dose reduction and $65.4 \%(17 / 26)$ of patients required dose interruption. The most common TEAEs leading to dose reduction were decreased appetite $(6 / 26 ; 23.1 \%)$, fatigue $(5 / 26 ; 19.2 \%)$, thrombocytopenia $(5 / 26 ; 19.2 \%)$, proteinuria $(4 / 26 ; 15.4 \%)$, and palmar-plantar erythrodysesthesia syndrome (3/26; 11.5\%). The most common TEAE leading to dose interruption was cholangitis $(3 / 16 ; 11.5 \%)$. Patients received a median of 4.0 cycles (range, 1 to 40 cycles) of lenvatinib; 6 patients received $\geq 10$ cycles. The median duration of treatment was 3.1 months (range, 0.5 to 36.8 months). 
Table 1 Baseline Characteristics

\begin{tabular}{ll}
\hline Category & $\begin{array}{l}\text { Patients Treated With Lenvatinib } \\
\mathbf{2 4} \mathbf{~ m g} \text { Once Daily }(\boldsymbol{N}=\mathbf{2 6})\end{array}$ \\
\hline $\begin{array}{l}\text { Median age, years (range) } \\
\text { Age group, } \mathbf{n}(\%)\end{array}$ & $64(41-78)$ \\
$\quad<65$ years & $14(53.8)$ \\
$\quad \geq 65$ years & $12(46.2)$ \\
Median weight, $\mathbf{k g}$ (range) & $56.9(41.5-77.8)$ \\
Sex, $\mathbf{n}(\%)$ & \\
$\quad$ Male & $15(57.7)$ \\
Female & $11(42.3)$
\end{tabular}

ECOG PS, n (\%)

$$
0
$$$$
1
$$

Primary tumor location, $\mathbf{n}(\%)$

$\begin{array}{ll}\text { Intrahepatic bile duct } & 6(23.1) \\ \text { Extrahepatic bile duct } & 8(30.8) \\ \text { Perihilar } & 1(3.8) \\ \text { Distal } & 7(26.9) \\ \text { Gallbladder } & 10(38.5) \\ \text { Ampulla of Vater } & 2(7.7)\end{array}$

Tumor lesions at screening, $\mathrm{n}(\%)$

Adrenal
Ascites
Bile duct $^{\mathrm{a}}$
Gallbladder $^{\mathrm{a}}$
Bone
Breast
Liver
Lung
Lymph node
Peritoneal
Lesion size ${ }^{\mathbf{b}}$, $\mathbf{n}$ (\%)
$<20$ mm
$\geq 20$ mm
Median lesion size ${ }^{\mathbf{b}}$, mm (range)
Tumor marker (CA 19-9), median

Tumor marker (CA 19-9), median $\mathrm{U} / \mathrm{mL}$ (range)

Tumor marker (CA 19-9), n (\%)

$$
\begin{array}{ll}
\leq 152 \mathrm{U} / \mathrm{mL} & 12(46.2) \\
>152 \mathrm{U} / \mathrm{mL} & 14(53.8)
\end{array}
$$

\section{White blood cell count}

\begin{tabular}{|c|c|}
\hline Category & $\begin{array}{l}\text { Patients Treated With Lenvatinib } \\
24 \text { mg Once Daily }(N=26)\end{array}$ \\
\hline \multicolumn{2}{|l|}{ Hemoglobin } \\
\hline Median, g/dL (range) & $12.05(9.4-15)$ \\
\hline$\leq 12 \mathrm{~g} / \mathrm{dL}, \mathrm{n}(\%)$ & $13(50.0)$ \\
\hline$>12 \mathrm{~g} / \mathrm{dL}, \mathrm{n}(\%)$ & $13(50.0)$ \\
\hline \multicolumn{2}{|l|}{ Total bilirubin } \\
\hline Median, mg/dL (range) & $0.6(0.3-1.2)$ \\
\hline$\leq 0.66$ mg/dL, n (\%) & $16(61.5)$ \\
\hline$>0.66$ mg/dL, n (\%) & $10(38.5)$ \\
\hline \multicolumn{2}{|l|}{ Alkaline phosphatase } \\
\hline Median, U/L (range) & $321(136-1235)$ \\
\hline$\leq 247 \mathrm{U} / \mathrm{L}, \mathrm{n}(\%)$ & $6(23.1)$ \\
\hline$>247$ U/L, n (\%) & $20(76.9)$ \\
\hline \multicolumn{2}{|l|}{ Albumin } \\
\hline Median, g/dL (range) & $4.1(2.7-4.7)$ \\
\hline$\leq 3.56 \mathrm{~g} / \mathrm{dL}, \mathrm{n}(\%)$ & $1(3.8)$ \\
\hline$>3.56$ g/dL, n (\%) & $25(96.2)$ \\
\hline \multicolumn{2}{|c|}{ Previous anticancer surgery, $\mathrm{n}(\%)$} \\
\hline No & $20(76.9)$ \\
\hline Yes & $6(23.1)$ \\
\hline
\end{tabular}

Median, $/ \mathrm{mm}^{3}$ (range)
Table 1 Baseline Characteristics (Continued)

Prior chemotherapy to biliary tract cancer, $\mathbf{n}(\%)$

$\begin{array}{ll}\text { Adjuvant } & 2(7.7) \\ \mathrm{S}-1^{c} & 1(3.8) \\ \text { Gemcitabine } & 1(3.8) \\ \text { Therapeutic } & 26(100.0) \\ \text { Gemcitabine }+ \text { cisplatin } & 20(76.9) \\ \text { Gemcitabine }+\mathrm{S}-1^{c} & 6(23.1)\end{array}$

Duration of the previous gemcitabine-based combination chemotherapy, $\mathrm{n}(\%)$

$\begin{array}{ll}<6 \text { months } & 13(50.0) \\ \geq 6 \text { months } & 13(50.0)\end{array}$

CA cancer antigen, ECOG PS Eastern Cooperative Oncology Group performance status

${ }^{\mathrm{a}} 14$ Patients did not have lesions at the bile duct or gallbladder upon screening

ber investigator assessment

'Combination treatment consisting of tegafur, gimeracil, and oteracil

\section{Pharmacokinetic profile}

Lenvatinib trough plasma concentrations in Japanese patients with BTC were comparable to the levels seen in a previous study of Japanese patients with DTC (Study 303) [20]. Plasma concentrations and body-weightadjusted plasma concentrations from both studies at C1D15 are shown in Fig. 4.

\section{Discussion}

Here, we report the results of a phase 2 study evaluating lenvatinib as a second-line treatment option in 
Table 2 Efficacy Outcomes

\begin{tabular}{|c|c|c|}
\hline \multirow[t]{2}{*}{ Category } & \multicolumn{2}{|c|}{ Patients Treated With Lenvatinib 24 mg Once Daily $(N=26)$} \\
\hline & Investigator Assessment & IIR \\
\hline $\begin{array}{l}\text { Objective response rate, } n(\%) \\
(90 \% \mathrm{Cl})\end{array}$ & $\begin{array}{l}3(11.5) \\
(3.2-27.2)\end{array}$ & $\begin{array}{l}3(11.5) \\
(3.2-27.2)\end{array}$ \\
\hline \multicolumn{3}{|l|}{ Best overall response, $\mathrm{n}(\%)$} \\
\hline Complete response & 0 & 0 \\
\hline Partial response & $3(11.5)$ & $3(11.5)$ \\
\hline Stable disease & $19(73.1)$ & $9(34.6)$ \\
\hline Progressive disease & $4(15.4)$ & $13(50.0)$ \\
\hline Not evaluable & 0 & 0 \\
\hline Unknown & 0 & $1(3.8)$ \\
\hline $\begin{array}{l}\text { Disease control rate }{ }^{a}, \mathrm{n}(\%) \\
(90 \% \mathrm{Cl})\end{array}$ & $\begin{array}{l}22(84.6) \\
(68.2-94.6)\end{array}$ & $\begin{array}{l}12(46.2) \\
(29.2-63.8)\end{array}$ \\
\hline $\begin{array}{l}\text { Clinical benefit rate }{ }^{b}, \mathrm{n}(\%) \\
(90 \% \mathrm{Cl})\end{array}$ & $\begin{array}{l}10(38.5) \\
(22.6-56.4)\end{array}$ & $\begin{array}{l}6(23.1) \\
(10.6-40.5)\end{array}$ \\
\hline PFS rate at 12 weeks, $\%(95 \% \mathrm{Cl})$ & $72.2(50.4-85.7)$ & $44.0(24.5-61.9)$ \\
\hline Median PFS, months (95\% Cl) & $3.19(2.79-7.23)$ & $1.64(1.41-3.19)$ \\
\hline Median time to progression, months $(95 \% \mathrm{Cl})$ & $4.11(2.76-7.39)$ & $1.64(1.41-2.92)$ \\
\hline Median overall survival, months $(95 \% \mathrm{Cl})$ & \multicolumn{2}{|c|}{$7.35(4.50-11.27)$} \\
\hline
\end{tabular}

Cl confidence interval, IIR independent imaging review, PFS progression-free survival

${ }^{\text {a }}$ The proportion of patients with a best overall response of complete response, partial response or stable disease; stable disease needed to be achieved at cycle 2 day 8 or later

${ }^{\text {b}}$ The proportion of patients with complete response + partial response + durable stable disease ( $\geq 23$ weeks)

patients with BTC who have failed gemcitabine-based therapy. The ORR was $11.5 \%$ (90\% CI: 3.2-27.2) per investigator assessment and per IIR. There was a notable difference in the number of patients considered to have achieved stable disease between investigator assessment $(n=19)$ and IIR $(n=9)$. Potentially, this was because of the reviewers' differing perception of the response based on RECIST version 1.1 criteria. Because numerous factors are considered in the determination of progressive versus stable disease, including both change in target and nontarget lesions, and overall tumor burden, individual reviewers may evaluate the response differently. Lenvatinib demonstrated antitumor activity with a median OS of 7.35 months (95\% CI: 4.50-11.27) and a median PFS (per investigator assessment) of 3.19 months (95\% CI: 2.79-7.23) (vs 1.64 months per IIR; 95\% CI: 1.41-3.19).

Recent studies have investigated other second-line therapy options: one phase 3 study (NCT01926236) suggested that the modified FOLFOX (mFOLFOX) chemotherapy regimen consisting of oxaliplatin and 5-fluorouracil should be considered the default second-line treatment for advanced/metastatic BTC [22]. The results of this study, which evaluated active symptom control (ASC) versus ASC plus mFOLFOX, were presented at ASCO 2019. The ASCO presentation reported a median OS of 6.2 months [22], median PFS of 4.0 months, ORR of $5 \%$, and DCR of $33 \%$ in the ASC plus mFOLFOX arm. A statistically significant $(P=0.031)$ and clinically meaningful improvement in OS was observed in patients treated with ASC plus mFOLFOX versus ASC alone. Another chemotherapy regimen, FOLFIRINOX, demonstrated efficacy in a phase 2 trial of patients with BTC who had experienced disease progression following treatment with cisplatin and gemcitabine: median PFS and OS were 6.2 and 10.7 months, respectively [23, 24]. Also, Abou-Alfa et al. [25] evaluated ivosidenib versus placebo in patients with advanced cholangiocarcinoma (primarily intrahepatic) and an isocitrate dehydrogenase 1 (IDH1) gene mutation. Of note, this population differed from our study, which enrolled patients without regard to a specific gene mutation. This phase 3 study, which allowed crossover from placebo to ivosidenib, reported the first positive PFS data of molecularly targeted therapy in cholangiocarcinoma [25]. Median PFS was 2.7 months versus 1.4 months in the ivosidenib and placebo arms, respectively (hazard ratio $0.37 ; 95 \%$ CI: $0.25-0.54 ; \quad P<0.001$ ). Median OS was longer in the ivosidenib arm versus placebo (10.8 vs 9.7 months) but these results were not significant $(P=0.06)$ [25].

Previous studies have evaluated the efficacy of other tyrosine kinase inhibitors in the treatment of patients with advanced BTC [26-29]. A phase 2 study of regorafenib as second-line treatment in 43 patients with metastatic BTC demonstrated favorable results 


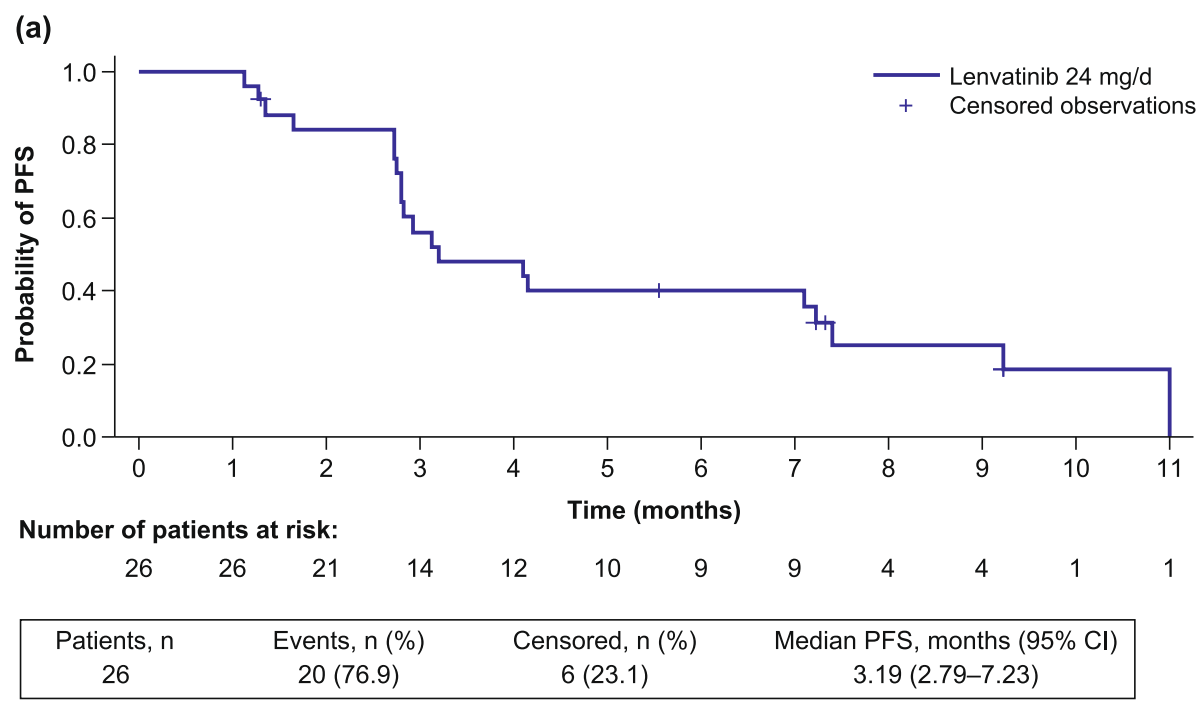

(b)

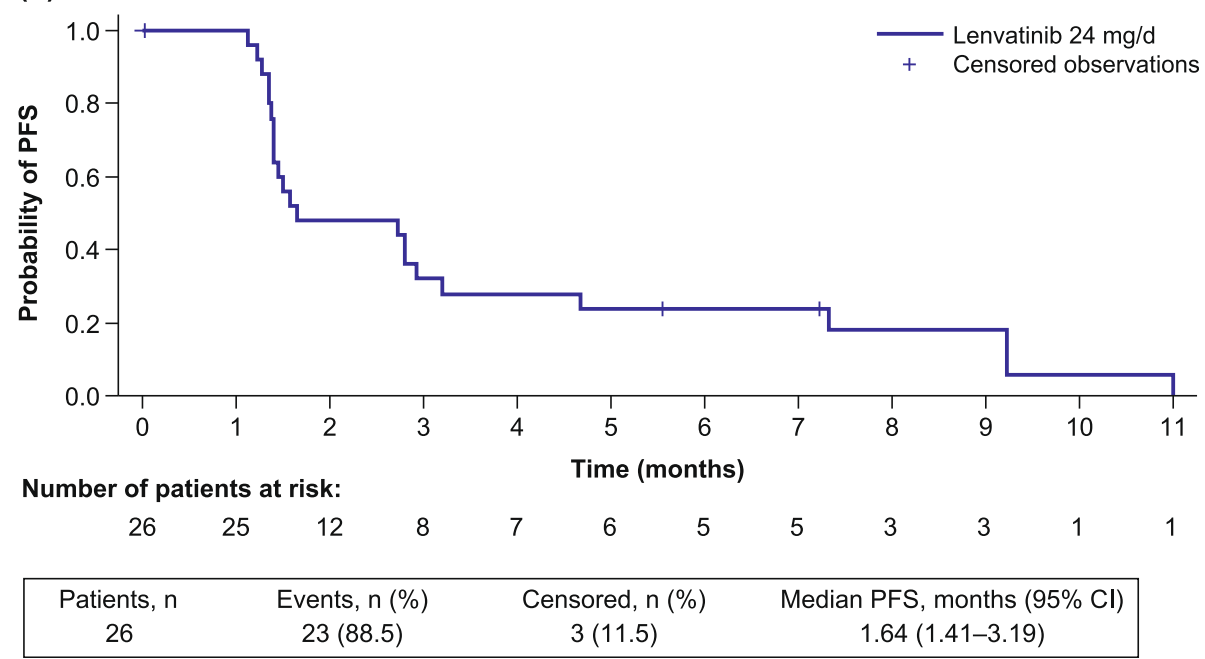

Fig. 1 Kaplan-Meier plot of PFS by investigator assessment (a) and IIR (b). Cl, confidence interval; IIR, independent imaging review; PFS, progression-free survival

with $11 \%(n=5)$ of patients achieving a partial response and a median PFS of 15.6 weeks (90\% CI: 12.9-24.7 weeks) [27], which is approximately 3.9 months. Sunitinib demonstrated marginal efficacy as second-line treatment in a phase 2 study $(n=56)$ of metastatic BTC with a median time to progression of 1.7 months (95\% CI: $1.0-2.4$ ) and an ORR of $8.9 \%$ [28]. Lastly, a phase 2 study of sorafenib in patients with unresectable or metastatic gallbladder carcinoma and cholangiocarcinoma demonstrated a median PFS of 3 months (95\% CI: 2-4) but was terminated early because it failed to meet the primary objective (ORR of 20\%) [29]. However, a pilot study of sorafenib versus best supportive care in patients with advanced intrahepatic cholangiocarcinoma demonstrated sorafenib has antitumor activity with a median PFS of 3.2 months (95\% CI: 2.4-4.1) and median OS of 5.7 months (95\% CI: 3.7-8.5) [26]. Additionally, several phase 2 trials evaluating tyrosine kinase inhibitors, such as apatinib (NCT03521219), infigratinib (NCT02150967), derazantinib (NCT03230318), erdafitinib (NCT02699606), and pemigatinib (NCT04256980), as second-line treatment options in patients with BTC are currently ongoing [23].

In addition to direct antitumor activity, lenvatinib has also demonstrated immunomodulatory activity. Research has shown that lenvatinib modulates cancer immunity in the immunocompetent tumor microenvironment by reducing the population of tumor-associated macrophages 


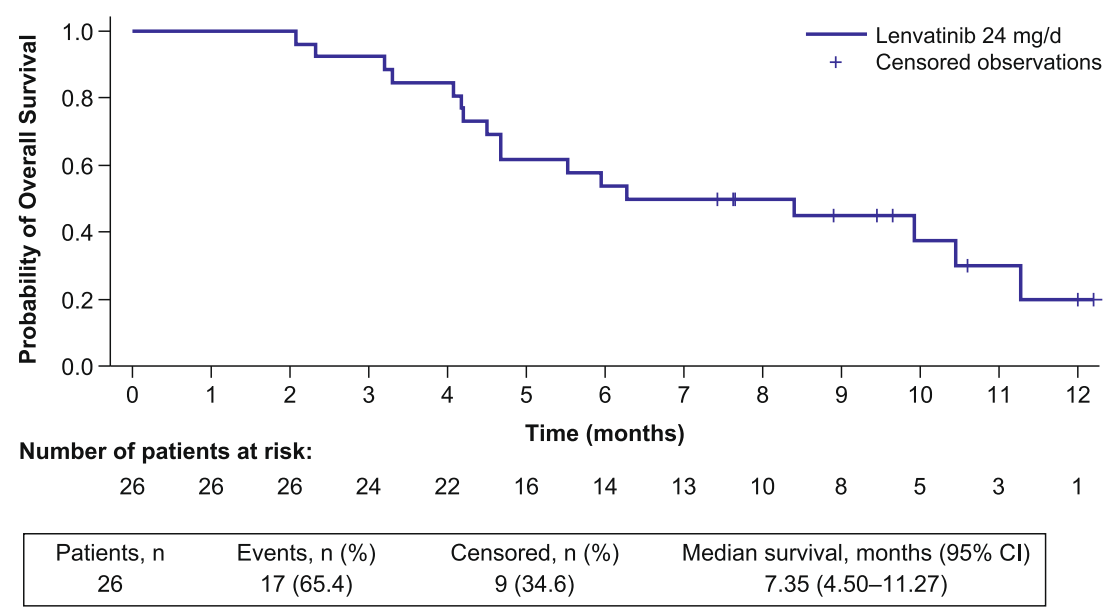

Fig. 2 Kaplan-Meier plot of OS. ${ }^{a} 17$ Deaths occurred in this study; 2 deaths occurred within 30 days of administration of the last dose and 15 deaths occurred $>30$ days after administration of the last dose. Cl, confidence interval; OS, overall survival

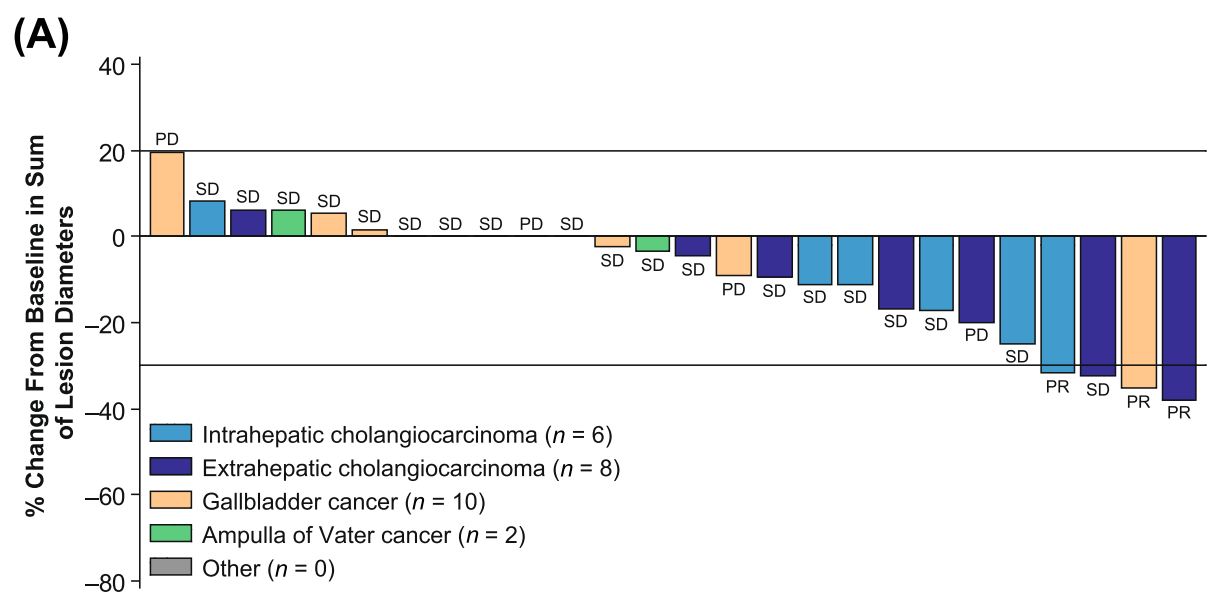

(B)

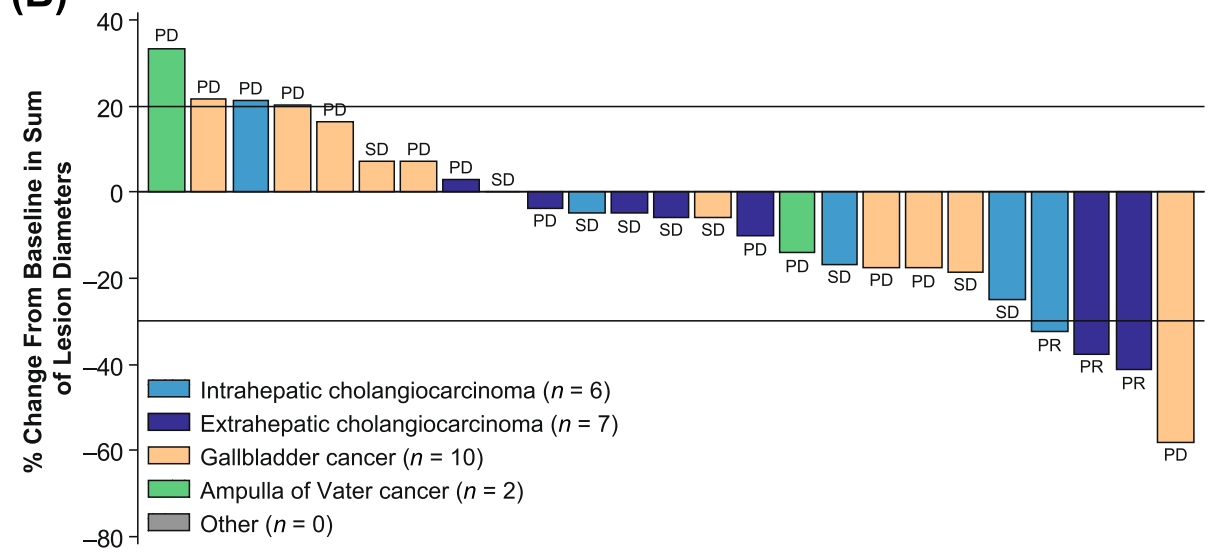

Fig. 3 Percentage change from baseline in the sum of lesion diameters per investigator assessment (A) and IIR (B). ${ }^{2}$ One patient was assigned a BOR of "unknown" by IIR and was excluded from this analysis. BOR, best overall response; IIR, independent imaging review; PD, progressive disease; PR, partial response; SD, stable disease 
Table 3 Treatment-emergent Adverse Events That Occurred in $\geq 10 \%$ of Patients

\begin{tabular}{|c|c|c|}
\hline \multirow{2}{*}{$\begin{array}{l}\text { TEAE }^{\mathrm{a}} \\
\text { Patients with any-grade TEAE, } \mathrm{n}(\%)\end{array}$} & \multicolumn{2}{|c|}{$\begin{array}{l}\text { Patients Treated With } \\
\text { Lenvatinib } 24 \text { mg Once } \\
\text { Daily }(N=26)\end{array}$} \\
\hline & $26(100)$ & \\
\hline Patients with any TEAE $\geq$ grade $3, n(\%)$ & $21(80.8)$ & \\
\hline Preferred term, $n(\%)$ & Any grade & Grade 3 or 4 \\
\hline Hypertension & $22(84.6)$ & $10(38.5)$ \\
\hline Dysphonia & $16(61.5)$ & 0 \\
\hline Proteinuria & $16(61.5)$ & $3(11.5)$ \\
\hline Palmar-plantar erythrodysesthesia syndrome & $15(57.7)$ & $3(11.5)$ \\
\hline Decreased appetite & $14(53.8)$ & $3(11.5)$ \\
\hline Thrombocytopenia & $14(53.8)$ & $1(3.8)$ \\
\hline Fatigue & $13(50.0)$ & 0 \\
\hline Hypothyroidism & $12(46.2)$ & 0 \\
\hline Peripheral edema & $9(34.6)$ & 0 \\
\hline Constipation & $8(30.8)$ & 0 \\
\hline Decreased weight & $8(30.8)$ & 0 \\
\hline Diarrhea & $8(30.8)$ & $1(3.8)$ \\
\hline Pyrexia & $8(30.8)$ & 0 \\
\hline Anemia & $6(23.1)$ & $3(11.5)$ \\
\hline Cholangitis & $6(23.1)$ & $4(15.4)$ \\
\hline Nausea & $6(23.1)$ & 0 \\
\hline Rash & $6(23.1)$ & $1(3.8)$ \\
\hline Upper abdominal pain & $6(23.1)$ & 0 \\
\hline Malaise & $5(19.2)$ & 0 \\
\hline Ascites & $4(15.4)$ & $2(7.7)$ \\
\hline Cancer pain & $4(15.4)$ & 0 \\
\hline Headache & $4(15.4)$ & 0 \\
\hline Myalgia & $4(15.4)$ & 0 \\
\hline Stomatitis & $4(15.4)$ & 0 \\
\hline Tumor pain & $4(15.4)$ & 0 \\
\hline Alopecia & $3(11.5)$ & 0 \\
\hline Bile duct obstruction & $3(11.5)$ & $2(7.7)$ \\
\hline Delirium & $3(11.5)$ & 0 \\
\hline Epistaxis & $3(11.5)$ & 0 \\
\hline Hypoalbuminemia & $3(11.5)$ & $2(7.7)$ \\
\hline Hypophosphatemia & $3(11.5)$ & $1(3.8)$ \\
\hline Lymphopenia & $3(11.5)$ & $2(7.7)$ \\
\hline Pruritis & $3(11.5)$ & 0 \\
\hline Vomiting & $3(11.5)$ & 0 \\
\hline
\end{tabular}

TEAE treatment-emergent adverse event

${ }^{\mathrm{a}}$ TEAEs were any adverse events that occurred between initiation of treatment and 30 days from last dose
Table 4 Treatment-related Adverse Events That Occurred in $\geq 10 \%$ of Patients

\begin{tabular}{|c|c|c|}
\hline TRAE & $\begin{array}{l}\text { Patients Tr } \\
\text { Lenvatinib } \\
\text { Daily }(N=\end{array}$ & $\begin{array}{l}\text { eated With } \\
24 \text { mg Once } \\
\text { 26) }\end{array}$ \\
\hline Patients with any-grade TRAE, n (\%) & $26(100)$ & \\
\hline Patients with any TRAE $\geq$ grade $3, n(\%)$ & $16(61.5)$ & \\
\hline Preferred term, $n(\%)$ & Any grade & Grade 3 or 4 \\
\hline Hypertension & $22(84.6)$ & $10(38.5)$ \\
\hline Dysphonia & $16(61.5)$ & 0 \\
\hline Palmar-plantar erythrodysesthesia syndrome & $15(57.7)$ & $3(11.5)$ \\
\hline Proteinuria & $15(57.7)$ & $3(11.5)$ \\
\hline Thrombocytopenia & $13(50.0)$ & $1(3.8)$ \\
\hline Decreased appetite & $12(46.2)$ & 0 \\
\hline Fatigue & $12(46.2)$ & 0 \\
\hline Hypothyroidism & $12(46.2)$ & 0 \\
\hline Decreased weight & $6(23.1)$ & 0 \\
\hline Diarrhea & $6(23.1)$ & 0 \\
\hline Anemia & $5(19.2)$ & $1(3.8)$ \\
\hline Malaise & $5(19.2)$ & 0 \\
\hline Nausea & $5(19.2)$ & 0 \\
\hline Peripheral edema & $5(19.2)$ & 0 \\
\hline Myalgia & $4(15.4)$ & 0 \\
\hline Stomatitis & $4(15.4)$ & 0 \\
\hline Alopecia & $3(11.5)$ & 0 \\
\hline Constipation & $3(11.5)$ & 0 \\
\hline Epistaxis & $3(11.5)$ & 0 \\
\hline Headache & $3(11.5)$ & 0 \\
\hline Rash & $3(11.5)$ & $1(3.8)$ \\
\hline Upper abdominal pain & $3(11.5)$ & 0 \\
\hline
\end{tabular}

TRAE treatment-related adverse event

(TAMs) and increasing the population of interferon- $\gamma-$ and granzyme-B-producing CD8+ T cells [30, 31]. Further, lenvatinib demonstrated enhanced antitumor activity preclinically via the interferon-signaling pathway in combination with a programmed cell death-1 (PD-1) inhibitor [31]. Atanasov et al. [32] evaluated the relationship between the prevalence of TAMs and tumor growth in patients with hilar cholangiocarcinoma, a subtype of BTC. This study reported that overall tumor recurrence was significantly higher in patients with high levels of TAMs at the tumor invasive fronts compared with patients with low levels of TAMs $(69.2 \%$ vs $33.3 \% ; P=0.015)$. Patients with high levels of TAMs experienced worse survival outcomes [32]. These preclinical data suggest that lenvatinib in combination with a PD-1 inhibitor may demonstrate further improved outcomes and therefore should be investigated. Further, a phase 2 trial of lenvatinib in 

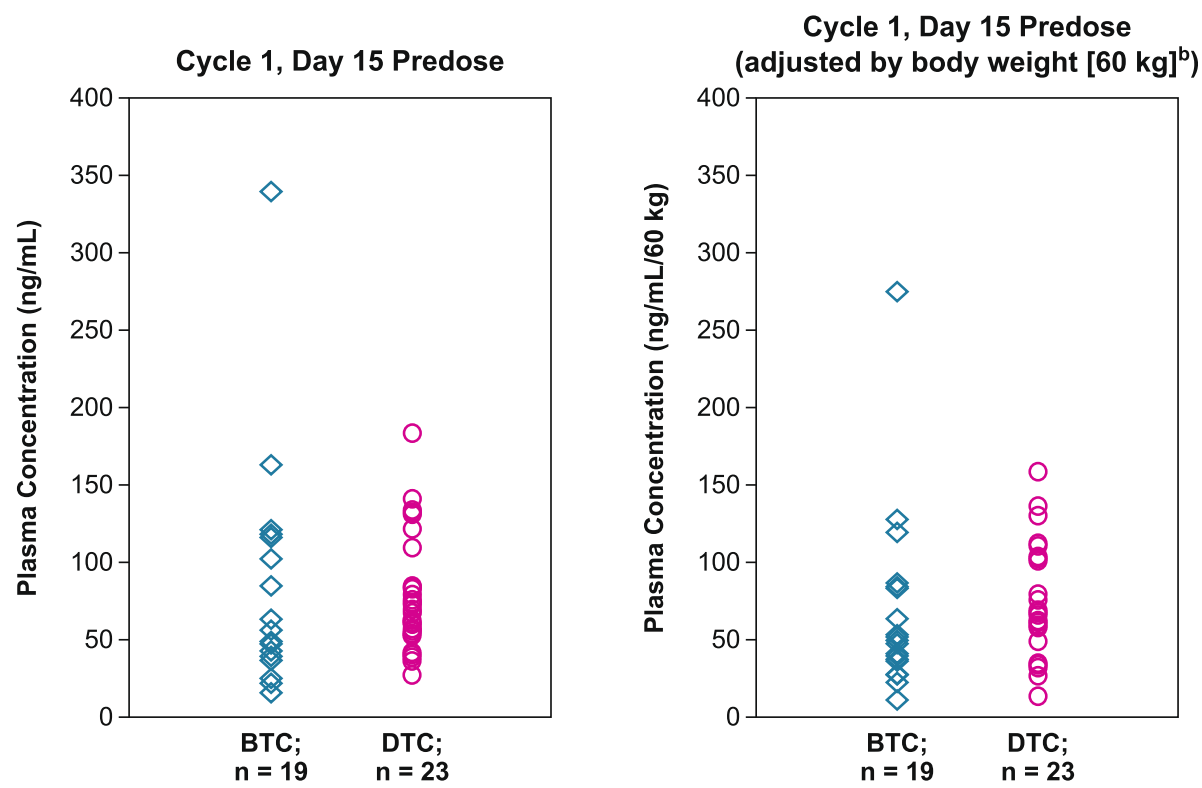

Fig. 4 Comparison of lenvatinib plasma concentration in patients with BTC (this study) to patients with DTC (Study 303) [20]. ${ }^{2}$ There were 7 patients excluded from the pharmacokinetic analysis because their dose was reduced or interrupted before cycle 1 day 15 . 'bodyweight-adjusted plasma concentration was calculated as follows: individual plasma concentration $\times$ bodyweight $[\mathrm{kg}] / 60[\mathrm{~kg}]$. BTC, biliary tract cancer; DTC, differentiated thyroid cancer

combination with pembrolizumab or nivolumab in patients with intrahepatic cholangiocarcinoma who previously received $\geq 2$ anticancer treatments, demonstrated promising results with an ORR of $21.4 \%$ and a median PFS of 5.9 months (95\% CI: 4.2-6.2) [23, 33]. Of note, studies of lenvatinib in combination with PD-1 inhibitors (pembrolizumab [NCT03797326] and nivolumab [JMA-IIA00436]) in patients with BTC are currently ongoing.

\section{Conclusions}

Lenvatinib demonstrated promising antitumor activity in patients with unresectable BTC who had failed gemcitabine-based chemotherapy. Additionally, the safety profile of lenvatinib in patients with BTC is similar to that previously reported in patients with other tumor types [34-36], and no new safety signals were identified. Toxicities were manageable with treatment modifications, dose reductions, or discontinuations. Noteworthy limitations of this study include the small sample size $(n=26)$, and the large diversity in BTC subgroups that were included (gallbladder cancer, $n=10$; intrahepatic cholangiocarcinoma, $n=6$; extrahepatic cholangiocarcinoma, $n=8$; and ampulla of Vater cancer, $n=2$ ). However, the inclusion of several BTC subgroups allows for easier trial enrollment, which in turn enables earlier clinical advances in the treatment of BTC. Further investigation of lenvatinib monotherapy or combination therapy with a PD-1 inhibitor as a potential second-line treatment option for patients with unresectable BTC is warranted, and ideally should be conducted in larger patient populations of each BTC subgroup.

\section{Abbreviations}

AE: Adverse event; ASC: Active symptom control; BTC: Biliary tract cancer; C\#D\#: Cycle \#, day \#; CBR: Clinical benefit rate; Cl: Confidence interval; DCR: Disease control rate; DTC: Differentiated thyroid cancer; ECOG PS: Eastern Cooperative Oncology Group performance status; FGFR : Fibroblast growth factor receptor; GC: Gemcitabine and cisplatin; GS: Gemcitabine plus S-1; IIR: Independent imaging review; mFOLFOX: modified FOLFOX; ORR: Objective response rate; OS: Overall survival; PD-1: Programmed cell death-1; PDGFR: Platelet-derived growth factor receptor; PFS: Progression-free survival; RECIST: Response Evaluation Criteria In Solid Tumors; TAM: Tumor-associated macrophages;

TEAE: Treatment-emergent adverse event; VEGF: Vascular endothelial growth factor

\section{Acknowledgments}

Data from this study were previously presented th the European Society for Medical Oncology (ESMO) meeting; September 8-12, 2019; Madrid, Spain. Study sponsored by Eisai Inc., Woodcliff Lake, NJ, USA, and Merck Sharp \& Dohme Corp., a subsidiary of Merck \& Co. Inc., Kenilworth, NJ, USA.

Medical writing support was provided by Jessica Pannu, PharmD, of Oxford PharmaGenesis Inc., Newtown, PA, USA.

\section{Authors' contributions}

All authors read and approved the submitted version of the manuscript and agree to be personally accountable for the author's own contributions and to ensure that questions related to the accuracy or integrity of any part of the work, even ones in which the author was not personally involved, have been appropriately investigated, resolved, and the resolution documented in the literature. In addition, specific contributions comprise: MI: Conceptualization, data curation, investigation, resources, validation, writing-review, and editing. $\mathrm{MU}, \mathrm{TS}, \mathrm{FN}, \mathrm{NM}, \mathrm{SS}$, and CM: Data curation, investigation, resources, validation, writing-review, and editing. HI: Conceptualization, formal analysis, investigation, methodology, resources, validation, visualization, writing-review, and editing. $\mathrm{NH}$ : Formal analysis, investigation, methodology, resources, validation, 
visualization, writing-review and editing. RN: Conceptualization, funding acquisition, investigation, project administration, resources, validation, writing-original draft, writing-review, and editing.

\section{Funding}

Eisai Inc., Woodcliff Lake, NJ, USA, funded the design of this analysis, data analysis, and data interpretation. The sponsors (Eisai Inc., Woodcliff Lake, NJ, USA, and Merck Sharp \& Dohme Corp., a subsidiary of Merck \& Co., Kenilworth, NJ, USA) participated in manuscript review, manuscript approval, and decision to submit for publication. The sponsors also funded the professional medical writer, who provided medical writing assistance.

\section{Availability of data and materials}

The data will not be available for sharing at this time as the data are commercially confidential. However, written requests to share the data will be considered on a case-by-case basis. To request data, please contact Dr. Masafumi Ikeda (email: masikeda@east.ncc.go.jp).

\section{Ethics approval and consent to participate}

This study was approved by the Institutional Review Board of the National Cancer Center at 5-1-1, Tsukiji, Chuo-ku, Tokyo, 104-0045, Japan (serial number: T4234). All patients provided written informed consent. This study was conducted in accordance with the World Medical Association Declaration of Helsinki, Good Clinical Practices, and local ethical/legal requirements.

\section{Consent for publication}

\section{Not applicable.}

\section{Competing interests}

Makoto Ueno: reports honoraria from Taiho Pharmaceutical, Yakult Honsha, AstraZeneca, Novartis, Lilly, Teijin Pharma, Shire, Ono Pharmaceutical, and Merck Serono; consulting or advisory role for Shire; research funding from Taiho Pharmaceutical, Shire, Daiichi Sankyo, Eisai, AstraZeneca, Ono Pharmaceutical, MSD, Merck Serono, NanoCarrier, Dainippon Sumitomo Pharma, Incyte, ASLAN Pharmaceuticals, and Yakult Honsha.

Masafumi Ikeda: reports honoraria from Abbott, Bayer, Bristol Myers Squibb, Dainippon Sumitomo Pharma, Eisai, Eli Lilly, Nobelpharma, Novartis, Otsuka, Taiho Pharmaceutical, Teijin Pharma, and Yakult Honsha; consulting or advisory role for Bayer, Daiichi Sankyo, Eisai, Kyowa Hakko Kirin, MSD, NanoCarrier, Novartis, Shire, Teijin Pharma, and Eli Lilly; research funding from ASLAN Pharmaceuticals, AstraZeneca, Baxalta/Shire, Bayer, Bristol Myers Squibb, Chugai Pharma, Eisai, Kowa, Kyowa Hakko Kirin, Lilly, Merck Serono, MSD, NanoCarrier, Novartis, Ono Pharmaceutical, Taiho Pharmaceutical, Takara Bio, and Yakult Honsha.

Takashi Sasaki: reports honoraria from Taiho Pharmaceutical and Eisai. Fumio Nagashima: reports honoraria from ASKA pharma, Chugai Pharma, Hisamitsu, Kyowa Hakko Kirin, Merck Serono, Mochida, Ono Pharmaceutical, Shionogi, Taiho Pharmaceutical, Takeda, and Yakult Honsha; research funding from AstraZeneca, Baxalta, Bayer, Chugai Pharma, Daiichi Sankyo, Dainippon Sumitomo Pharma, Eisai, Eli Lilly, J Pharma, Kyowa Hakko Kirin, Merck Serono, MSD, NanoCarrier, Mochida, Ono Pharmaceutical, Pfizer, Sanofi, Takeda, Yakult Honsha, and Zeria Pharma.

Nobumasa Mizuno: reports grants from Eisai, Merck Serono, AstraZeneca, Zeria Pharma, NanoCarrier, MSD, Dainippon Sumitomo Pharma, Novartis, ASLAN Pharmaceuticals, Incyte, Yakult Honsha, Pharma Valley Center, and Taiho Pharmaceutical; personal fees from Novartis, Yakult Honsha, Ono Pharmaceutical, OncoTherapy Science, Inc., Kyowa Hakko Kirin, Pfizer, Teijin Pharma and Taiho Pharmaceutical; non-financial support from Novartis, Yakult Honsha, Pfizer, and Bristol Myers Squibb.

Satoshi Shimizu: reports research funding from NanoCarrier, Eisai, Baxalta, Taiho Pharmaceutical, Dainippon Sumitomo Pharma, AstraZeneca, IQVIA services Japan K.K., and Incyte.

Hiroki Ikezawa: is an employee of Eisai Co., Ltd.

Nozomi Hayata: is an employee of Eisai Co., Ltd.

Ryo Nakajima: is an employee of Eisai Inc.

Chigusa Morizane: reports honoraria from Taiho Pharmaceutical, MSD,

Novartis, Teijin Pharma, Yakult Honsha, and Ono Pharmaceutical; consulting or advisory role for AstraZeneca, Taiho Pharmaceutical, Ono Pharmaceutical, MSD, Yakult Honsha, AbbVie, and Novartis; research funding from Eisai, Yakult Honsha, Ono Pharmaceutical, Taiho Pharmaceutical, J Pharma, Pfizer, AstraZeneca, and Merck Biopharma.

\section{Author details}

${ }^{1}$ Kanagawa Cancer Centre Hospital, Yokohama, Japan. ${ }^{2}$ Department of Hepatobiliary and Pancreatic Oncology, National Cancer Center Hospital East, 6-5-1 Kashiwanoha, Kashiwa 277-8577, Japan. ${ }^{3}$ Cancer Institute Hospital of JFCR, Tokyo, Japan. ${ }^{4}$ Kyorin University, Tokyo, Japan. ${ }^{5}$ Aichi Cancer Centre Hospital, Nagoya, Japan. ${ }^{6}$ Saitama Cancer Centre, Saitama, Japan. ${ }^{7}$ Eisai Co. Ltd., Tokyo, Japan. ${ }^{8}$ Eisai Inc., Woodcliff Lake, NJ, USA. ${ }^{9}$ National Cancer Centre Hospital, Tokyo, Japan.

\section{Received: 4 June 2020 Accepted: 31 August 2020}

\section{Published online: 16 November 2020}

\section{References}

1. Tariq NU, McNamara MG, Valle JW. Biliary tract cancers: current knowledge, clinical candidates and future challenges. Cancer Manag Res. 2019;11:262342.

2. Marcano-Bonilla L, Mohamed EA, Mounajjed T, Roberts LR. Biliary tract cancers: epidemiology, molecular pathogenesis and genetic risk associations. Chin Clin Oncol. 2016;5:61.

3. Van Dyke AL, Shiels MS, Jones GS, Pfeiffer RM, Petrick JL, Beebe-Dimmer JL, et al. Biliary tract cancer incidence and trends in the United States by demographic group, 1999-2013. Cancer. 2019;125:1489-98.

4. National Comprehensive Cancer Network Clinical Practice Guidelines in Oncology (NCCN Guidelines ${ }^{\circledast}$ ). Hepatobiliary Cancers. Version 4.2019. https:// www.nccn.org/professionals/physician_gls/pdf/hepatobiliary.pdf. Accessed 3 Jan 2020.

5. GBD 2017 Causes of Death Collaborators. Global, regional, and national agesex-specific mortality for 282 causes of death in 195 countries and territories, 1980-2017: a systematic analysis for the Global Burden of Disease Study 2017. Lancet. 2018;392:1736-88.

6. Park JO, Oh DY, Hsu C, Chen JS, Chen LT, Orlando M, et al. Gemcitabine plus cisplatin for advanced biliary tract cancer: a systematic review. Cancer Res Treat. 2015;47:343-61.

7. Brandi G, Rizzo A, Dall'Olio FG, Felicani C, Ercolani G, Cescon M, et al. Percutaneous radiofrequency ablation in intrahepatic cholangiocarcinoma: a retrospective single-center experience. Int J Hyperth. 2020;27:479-85.

8. Morizane C, Okusaka T, Mizusawa J, Katayama H, Ueno M, Ikeda M, et al. Combination gemcitabine plus S-1 versus gemcitabine plus cisplatin for advanced/recurrent biliary tract cancer: the FUGA-BT (JCOG1113) randomized phase III clinical trial. Ann Oncol. 2019;30:1950-8.

9. Sakai D, Kanai M, Kobayashi S, Eguchi H, Baba H, Seo S, et al. Randomized phase III study of gemcitabine, cisplatin plus S-1 (GCS) versus gemcitabine, cisplatin (GC) for advanced biliary tract cancer (KHBO1401-MITSUBA) [abstract]. Ann Oncol. 2018;29(Suppl 8):Abstract 6150.

10. Yoshikawa D, Ojima H, Iwasaki M, Hiraoka N, Kosuge T, Kasai S, et al. Clinicopathological and prognostic significance of EGFR, VEGF, and HER2 expression in cholangiocarcinoma. Br J Cancer. 2008;98:418-25.

11. Giatromanolaki A, Koukourakis MI, Simopoulos C, Polychronidis A, Sivridis E. Vascular endothelial growth factor (VEGF) expression in operable gallbladder carcinomas. Eur J Surg Oncol. 2003;29:879-83.

12. Xu YF, Yang XQ, Lu XF, Guo S, Liu Y, labal M, et al. Fibroblast growth factor receptor 4 promotes progression and correlates to poor prognosis in cholangiocarcinoma. Biochem Biophys Res Commun. 2014;446:54-60.

13. Boonjaraspinyo S, Boonmars T, Wu Z, Loilome W, Sithithaworn P, Nagano I, et al. Platelet-derived growth factor may be a potential diagnostic and prognostic marker for cholangiocarcinoma. Tumour Biol. 2012;33:1785-802.

14. Matsui J, Yamamoto Y, Funahashi Y, Tsuruoka A, Watanabe T, Wakabayashi T, et al. E7080, a novel inhibitor that targets multiple kinases, has potent antitumor activities against stem cell factor producing human small cell lung cancer H146, based on angiogenesis inhibition. Int J Cancer. 2008;122: 664-71.

15. Okamoto K, Kodama K, Takase K, Sugi NH, Yamamoto Y, Iwata M, et al. Antitumor activities of the targeted multi-tyrosine kinase inhibitor lenvatinib (E7080) against RET gene fusion-driven tumor models. Cancer Lett. 2013; 340:97-103.

16. Yamamoto Y, Matsui J, Matsushima T, Obaishi H, Miyazaki K, Nakamura K, et al. Lenvatinib, an angiogenesis inhibitor targeting VEGFR/FGFR, shows broad antitumor activity in human tumor xenograft models associated with microvessel density and pericyte coverage. Vasc Cell. 2014;6:18.

17. Tohyama O, Matsui J, Kodama K, Hata-Sugi N, Kimura T, Okamoto K, et al. Antitumor activity of lenvatinib (e7080): an angiogenesis inhibitor that 
targets multiple receptor tyrosine kinases in preclinical human thyroid cancer models. J Thyroid Res. 2014;2014:638747.

18. Eisai Co., Ltd. Eisai and MSD Japan commence collaboration on commercialization activities for Lenvima ${ }^{\oplus}$ (lenvatinib) in Japan [press release]. Published October 22, 2018. https://www.eisai.com/news/2018/ news201888.html. Accessed 3 Jan 2020

19. Ikeda M, Sasaki T, Morizane C, Mizuno N, Nagashima F, Shimizu S, et al. A phase 2 study of lenvatinib monotherapy as second-line treatment in unresectable biliary tract cancer: Primary analysis results [abstract]. Ann Oncol. 2017;28(Suppl 5):246. Abstract 722P.

20. Nagahama M, Ozeki T, Suzuki A, Sugino K, Niioka T, Ito K, et al. Association of lenvatinib trough plasma concentrations with lenvatinib-induced toxicities in Japanese patients with thyroid cancer. Med Oncol. 2019;36:39.

21. Fornaro L, Cereda S, Aprile G, Di Girolamo S, Santini D, Silvestris N, et al. Multivariate prognostic factors analysis for second-line chemotherapy in advanced biliary tract cancer. Br J Cancer. 2014;1 10:2165-9.

22. Lamarca A, Palmer DH, Wasan HS, Ross PJ, Ma YT, Arora A, et al. ABC-06 |A randomised phase III, multi-centre, open-label study of active symptom control (ASC) alone or ASC with oxaliplatin / 5-FU chemotherapy (ASC+ mFOLFOX) for patients (pts) with locally advanced / metastatic biliary tract cancers (ABC) previously-treated with cisplatin/gemcitabine (CisGem) chemotherapy [abstract]. J Clin Oncol. 2019;37(15 Suppl):Abstract 4003.

23. Rizzo A, Ricci AD, Tober N, Nigro MC, Mosca M, Palloni A, et al. Second-line treatment in advanced biliary tract cancer: today and tomorrow. Anticancer Res. 2020;40:3013-30.

24. Belkouz A, de Vos-Geelen J, Mathôt RAA, Eskens FALM, van Gulik TM, van Oijen MGH, et al. Efficacy and safety of FOLFIRINOX as salvage treatment in advanced biliary tract cancer: an open-label, single arm, phase 2 trial. Br J Cancer. 2020;122:634-9.

25. Abou-Alfa GK, Macarulla Mercade T, Javle M, Kelley RK, Lubner S, Adeva J, et al. ClarlDHy: A global, phase III, randomized, double-blind study of ivosidenib (IVO) vs placebo in patients with advanced cholangiocarcinoma (CC) with an isocitrate dehydrogenase 1 (IDH1) mutation [abstract]. Ann Oncol. 2019;30(Suppl 5):Abstract LBA10_PR.

26. Luo X, Jia W, Huang Z, Li X, Xing B, Jiang X, et al. Effectiveness and safety of sorafenib in the treatment of unresectable and advanced intrahepatic cholangiocarcinoma: a pilot study. Oncotarget. 2017;8:17246-57.

27. Sun W, Patel A, Normolle D, Patel K, Ohr J, Lee JJ, et al. A phase 2 trial of regorafenib as a single agent in patients with chemotherapy-refractory, advanced, and metastatic biliary tract adenocarcinoma. Cancer. 2019;125: 902-9.

28. Yi JH, Thongprasert S, Lee J, Doval DC, Park SH, Park JO, et al. A phase II study of sunitinib as a second-line treatment in advanced biliary tract carcinoma: a multicentre, multinational study. Eur J Cancer. 2012;48:196201.

29. El-Khoueiry AB, Rankin CJ, Ben-Josef E, Lenz HJ, Gold PJ, Hamilton RD, et al. SWOG 0514: a phase II study of sorafenib in patients with unresectable or metastatic gallbladder carcinoma and cholangiocarcinoma. Investig New Drugs. 2012;30:1646-51.

30. Kato Y, Tabata K, Hori Y, Tachino S, Okamoto K, Matsui J. Effects of lenvatinib on tumor-associated macrophages enhance antitumor activity of PD-1 signal inhibitors [abstract]. Mol Cancer Ther. 2015;14(12 Suppl 2): Abstract A92.

31. Kato Y, Tabata K, Kimura T, Yachie-Kinoshita A, Ozawa Y, Yamada K, et al. Lenvatinib plus anti-PD-1 antibody combination treatment activates CD8+ T cells through reduction of tumor-associated macrophage and activation of the interferon pathway. PLoS One. 2019;14:e0212513.

32. Atanasov G, Hau HM, Dietel C, Benzing C, Krenzien F, Brandl A, et al. Prognostic significance of macrophage invasion in hilar cholangiocarcinoma. BMC Cancer. 2015;15:790.

33. Lin J, Shi W, Zhao S, Hu J, Hou Z, Yao M, et al. Lenvatinib plus checkpoint inhibitors in patients (pts) with advanced intrahepatic cholangiocarcinoma (ICC): preliminary data and correlation with next-generation sequencing [abstract]. J Clin Oncol. 2018;36(4 Suppl):Abstract 500.

34. Schlumberger $M$, Tahara M, Wirth $L$, Robinson B, Brose MS, Elisei R, et al. Lenvatinib versus placebo in radioiodine-refractory thyroid cancer. $N$ Engl J Med. 2015;372:621-30.

35. Motzer RJ, Hutson TE, Glen H, Michaelson MD, Molina A, Eisen T, et al. Lenvatinib, everolimus, and the combination in patients with metastatic renal cell carcinoma: a randomised, phase 2, open-label, multicentre trial. Lancet Oncol. 2015;16:1473-82.
36. Vergote I, Teneriello M, Powell MA, Miller DS, Garcia AA, Mikheeva ON, et al. A phase II trial of lenvatinib in patients with advanced or recurrent endometrial cancer: Angiopoietin-2 as a predictive marker for clinical outcomes [abstract]. J Clin Oncol. 2013;31(15 Suppl):Abstract 5520.

\section{Publisher's Note}

Springer Nature remains neutral with regard to jurisdictional claims in published maps and institutional affiliations.

\section{Ready to submit your research? Choose BMC and benefit from:}

- fast, convenient online submission

- thorough peer review by experienced researchers in your field

- rapid publication on acceptance

- support for research data, including large and complex data types

- gold Open Access which fosters wider collaboration and increased citations

- maximum visibility for your research: over $100 \mathrm{M}$ website views per year

At BMC, research is always in progress.

Learn more biomedcentral.com/submissions 